\title{
Validity and reliability of plant-based culinary nutrition model questionnaire for fitness among sports science students
}

\author{
Bina Baboo Morji ${ }^{1}$, Ahmad Zabidi Abdul Razak ${ }^{2}$ \& Sareena Hanim Hamzah ${ }^{\text {* }}$ \\ ${ }^{1}$ Centre for Sport and Exercise Sciences, University of Malaya, 50603 Kuala Lumpur, \\ Malaysia; ${ }^{2}$ Department of Educational Management, Planning and Policy, Faculty of \\ Education, University of Malaya, 50603 Kuala Lumpur, Malaysia
}

\begin{abstract}
Introduction: There is an emerging focus on plant-based foods that have the added advantage of being nutritious without side effects. Besides, its preparation with nutritional awareness and culinary skills could be an effective solution for improving personal fitness. This study aimed to determine validity and reliability of a questionnaire for the development of a plant-based culinary nutrition model for fitness among sports science students. Methods: This study employed exploratory sequential mixed method design and was carried out in two phases. Phase 1 employed a qualitative design utilising modified Delphi method to determine content validity index (CVI) of the questionnaire, while phase 2 was a quantitative design using Cronbach's alpha statistical analysis to evaluate reliability of the instrument. The questionnaire consisted of the need for plant-based culinary nutrition model (Section A) and the model's components (Section B). Thirteen expert panels from diverse expertise in sports nutrition and 30 sports science students took part. Results: Phase 1 resulted in development of a questionnaire where Section A and Section B scored CVI of 0.834 and 1.000, respectively. For phase 2, Cronbach's alpha score for reliability of the questionnaire was 0.836 with a total of 15 items. The Cronbach's alpha score for questionnaire items from Sections A and B were 0.709 and 0.832, respectively. Conclusion: The questionnaire developed in this study is validated and is considered reliable for use as a significant tool for plantbased culinary nutrition among sports science students.
\end{abstract}

Keywords: plant-based nutrition, culinary, health and fitness, sports science students

\section{INTRODUCTION}

Previous literature findings revealed that plant-based whole foods have the added benefits of being entirely healthy without side effects (Evans, 2015). Generally, plant-based diets are rich in carbohydrates, fibre, micronutrients, phytochemicals, and antioxidants. However, they contain lower calories, protein, vitamin B12, n-3 fats, calcium, and iodine. Hence, meal planning and management of food choices become crucial for the achievement of recommended energy and nutrient intakes. In addition, a well-planned plant-based diet can provide adequate amounts of all known nutrients for fitness and sports performance (Burke \& Hawley, 2018; Hever, 2016). Data indicated that all

\footnotetext{
*Corresponding author: Dr Sareena Hanim Binti Hamzah Centre for Sport and Exercise Sciences, University of Malaya, 50603 Kuala Lumpur, Malaysia Tel: +603-79673321; Fax: +603-79569590; Email: sareena@um.edu.my doi: https://doi.org/10.31246/mjn-2020-0114
} 
essential and non-essential amino acids can be supplied by plant food sources alone as long as a variety of foods is consumed and the energy intake to maintain fitness is adequate (Hever, 2016; Venderley \& Campbell, 2006).

A plant-based diet facilitates high intake of carbohydrate and protein, while at the same time maintains prolonged exercise, recovery, and repeated performance (PCRM, 2014; McAnulty, Holden \& Keith, 2001). Some of the popular plant-based diets being practised world-wide are lactovegetarian, ovo-lacto vegetarian, vegan, and raw vegan. Vegan diet which emphasises a complete removal of animal-based products from diet is also gaining popularity among the public and younger generations (Wirnitzer, 2018).

While healthy eating behaviour is being touted, similar emphasis is still lacking when it comes to instilling culinary skills from young. Fundamental culinary skills are choosing, preparing, and consuming foods prepared from 'scratch' (Caraher, 2015). Culinary skills are not only for professional chefs, but they are also practical techniques that everyone should master to maintain health and fitness. The merging of nutrition and food science with culinary skills has resulted in healthy eating behaviours due to increased confidence and nutrition awareness (Condrasky \& Hegler, 2010).

Plant-based culinary nutrition model is a model that includes both the fundamentals of nutrition and the basics of culinary skills to manage fitness. It was pursued to compliment various efforts and strategies taken by the Ministry of Health in managing fitness of the nation in general and sports science students specifically. Under these circumstances, a plantbased culinary nutrition model may be useful as a guidance for sport science students in managing their fitness better through plant-based nutritional knowledge and culinary skills. Besides that, there is a need for a plant-based culinary nutrition model for fitness due to the awareness, practicality and safety of consuming plant-based diets for sustainability, health, and ethical reasons. Many athletes and experts in the health and fitness industry or sports are receptive towards plant-based diet for fitness and performance, and have thus adopted plant-based lifestyle (Burke \& Hawley, 2018). In the local scenario, a plant-based culinary nutrition model for fitness is perhaps anticipated to guide sports science students with a healthier diet preference for optimum fitness. Therefore, the validity and reliability of a suitable questionnaire play an important role in developing a useful plant-based culinary nutrition model.

The aim of testing for validity is to determine if the instrument measures what it was intended to measure, and whether it is usable (Oluwatayo, 2012). Validity is also viewed as an indication of the extent to which a research conclusion reflects reality (White \& McBurney, 2012); whereas reliability is referred as dependability and replicability, striving for accuracy and comprehensiveness of a survey instrument. One of the ways to test reliability is through Cronbach's alpha. It measures internal consistency reliability based on the average interitem correlation of an instrument (Koonce \& Kelly, 2014).

While validity is about the capacity of an instrument to quantify the properties of the construct (Barton, Wrieden \& Anderson, 2011), reliability is the consistency of a measure. Hence, the questionnaire needs to be validated and tested for reliability in order to be a reliable data collection tool for the development of plant-based culinary nutrition-related studies. Thus, the aim of this study was to determine the validity and reliability of the survey instrument developed for data collection. These valuable data will measure the need and significance of developing a plant-based culinary nutrition 
model for fitness among sports science students.

\section{MATERIALS AND METHODS}

\section{Study design}

This study employed a mixed method exploratory sequential design which consisted of two phases. Phase 1 was qualitative data collection that utilised the modified Delphi technique, whereas phase 2 was quantitative data collection. In phase 1 , the reporting of interview with expert panel members used the Consolidated Criteria for Reporting Qualitative Research (COREQ) as a guideline (Tong, Sainsbury \& Craig, 2018). It is a formal reporting checklist for in-depth interviews and focus groups. The reporting of expert panel's interview in the current research was based on three main domains in COREQ. These included researcher or research team and reflexivity, study design, and analysis and findings. Meanwhile, content validity ratio (CVR) was used for quantitative assessment of the content validity (Ayre \& Scally, 2014). This was done by simplifying the information into CVR Worksheet that calculated the CVR for an item and content validity index (CVI) value for the overall instrument (Lawshe, 1975).

In phase 2, there were four research questions to answer: (1) how far experts perceive the importance of having a plant-based culinary nutrition model for fitness; (2) what are the components of plant-based culinary nutrition model for fitness; (3) what is the consensus level of experts on components in plant-based culinary nutrition model; and (4) what is the process of plant-based culinary nutrition model development. These were answered through responses from the expert panel, whereas the survey items were built from consensus by the experts.

\section{Participants}

For phase 1 of the study, participants were a panel of experts chosen based on purposive sampling. The panel of 13 experts identified and interviewed were subject matter experts in the area of sports nutrition and dietetics, coaching, athletics, academicians, sports scientists, and a locally and internationally renowned Emeritus Professor in Nutritional Sciences. Of these, three experts were practising a plant-based diet in their daily life. There are no strict rules on the number of experts required for this study (Thangaratinam \& Redman, 2005).

The recruitment was conducted through personal contacts of supervisors and web search. Official email invitation was sent to the experts as well. This email also served as a consent to be interviewed at expert's time and venue of convenience without any obligation or monetary gain. Confidentiality was maintained throughout recruitment, interview process, and data analysis. The replies from experts were via emails and text messaging. Table 1 shows the demographic information of expert panels.

Phase 2 involved the recruitment of sports science students from a local public university and data collection on reliability. These students were between 19-25 years old pursuing various degree programmes in Sports Science. They were selected as the subjects for phase 2 of the study in order to equip sports science students with an alternative diet option with relevant culinary skills applicable for managing fitness. Samples were calculated based on a flat rule of thumb in which a single number is recommended for any situation. For the current research, a flat rule of thumb by Browne (1995), which is a sample size of 30 was adopted (PASS Sample Size Software, 2019). This research was conducted with the approval of the University of Malaya Research Ethics Committee (UM.TNC2/UMREC-431). The participants provided their written informed consent. 


\section{Development of instrument by using Delphi technique}

The research instrument, a questionnaire, was developed based on the modified Delphi method (Thangaratinam \& Redman, 2005). It was appropriate because it involved faceto-face and individual interview with each expert. It also used open-ended questions that allowed flow of opinions, ideas, suggestions, and experience sharing. External experts were engaged during validation process. Data were collected thru in-depth interviews by using open-ended questions: (1) what do you know about plant-based diet; (2) what is your opinion on the research that shows plant-based culinary nutrition is able to manage fitness; (3) should plant-based culinary nutrition be introduced as a course or programme in the current sports nutrition curriculum at higher learning institutions; (4) what components of plant-based culinary nutrition should be included into the plant-based culinary nutrition model for fitness.

\section{Development of questionnaire}

The qualitative data were analysed by using modified Delphi for three rounds. The interview with expert panel was recorded, transcribed verbatim, and coded manually based on Saldana's coding methods (Onwuegbuzie, Frels \& Hwang, 2016). A consistent approach to coding is important to ensure the credibility of data analysed. There were four steps in the qualitative data analysis. The first step was basically transcribing each interview, whereas the second step involved the transfer of the completed transcription data onto Microsoft Excel sheet and analysed to view the similarities or differences between expert views. The third step was initial coding in which the code was either a word or phrase that represented aspects of a research question. They were examined to identify patterns and frequency. The last step was the assigning of labels to research questions in the form of anchor codes. Under each anchor code, there was a compilation of initial codes used to generate categories.

Categories would have larger viewpoints which were then condensed further into Themes 2 and further narrowed into Themes 3 . Themes were used to guide the development of the

Table 1. Demographic information for expert panels based on COREQ checklist

\begin{tabular}{ll}
\hline Experts & Expertise \\
\hline 1 & $\begin{array}{l}\text { Dietitian and assistant director (sports performance) at National Sports } \\
\text { Institute, Malaysia }\end{array}$ \\
3 & Sports nutrition lecturer \\
4 & Director, Division of research and innovation, Sports Institute \\
5 & Head of Food service department, Sports Council \\
6 & Executive chef, Sports Council \\
7 & Sports medicine specialist \\
8 & Sports coach and tower runner \\
9 & Endurance sports coach \\
10 & Endurance sports coach \\
11 & Head of postgraduate studies, Faculty of Sports Science \& Recreation \\
12 & Plant-based sports scientist \\
13 & Emeritus Professor in nutrition \\
\hline
\end{tabular}


survey instrument, which eventually answered the research questions. Based on the analysis of themes and also literature review, it was possible to generate items for the questionnaire and eventually a questionnaire draft based on a 5-point Likert scale (1=disagree; $2=$ slightly disagree; $3=$ neither agree nor disagree; 4=agree; 5=strongly agree) (Simon \& White, 2016). There were two parts and a total of 20 items in the questionnaire draft. Part 1 was the demographics of the respondents. Part 2 had Section A with 12 items about the need to develop a plant-based culinary nutrition model for fitness, and Section $\mathrm{B}$ about the components in the model, which consisted of 8 components.

\section{Generation of items}

The drafted questionnaire was distributed to six experts for feedback, as well as face and content validity analysis. The standard number of experts required for Delphi studies is still ambiguous (Hsu, 2007). However, in the present study, the selection of six experts was based on their willingness to participate in the following rounds. They were requested to provide comments and suggestions to improve the instrument.

Experts had to fill in an Expert Validation form, which was adapted from Survey/Interview Validation Rubric for Expert Panel (VREP) (Simon \& White, 2016). Experts had to score each criterion with a range of $1=$ not acceptable (major modifications needed); 2=below expectations (some modifications needed); $3=$ meets expectations (no modifications needed but could be improved with minor changes); and 4=exceeds expectations.

\section{Content validity}

Additionally, the six experts were required to complete the questionnaire. Content validity is basically the constancy of content made by experts based on their experience, knowledge, and wisdom in respective fields. Items that were given a response of $3=$ neither agree nor disagree; 4=agree; and 5=strongly agree were chosen for the calculation of CVR and CVI. Items with the scores of 1 =disagree and $2=$ slightly disagree were not considered for CVR and CVI calculation. CVI is the mean of CVR values of the retained items (Lawshe, 1975). Data collected were gathered and computed. An approach developed by Lawshe in 1975 was employed in this research. It was simplified into CVR Worksheet that calculated the CVR for an item and a CVI value for the overall instrument. The worksheet was based on the following formula:

$C V R=\frac{n_{e}-\left(\frac{N}{2}\right)}{\frac{N}{2}}$

Where $n_{\mathrm{e}}$ is the number of panelists indicating "essential" and $\mathrm{N}$ is the total number of panelists.

CVR score ensures the content is important and most accurate. The questions were designed in the best way to gauge the need of this model and the components that should go into the model.

$$
C V I=\frac{\text { Number of experts who give } 3 \text { or } 4 \text { to this item }}{\text { Total number of experts }}
$$

\section{Statistical analysis}

Internal consistency of the questionnaire was assessed to ensure reliability and it was measured by using the Cronbach's alpha. Results of reliability were expressed as mean \pm standard deviation. Furthermore, data collected from the respondents were statistically analysed using the Statistical Package for Social Sciences (SPSS) version 23 (IBM SPSS New York, United States, 2019).

\section{RESULTS AND DISCUSSION}

The aim of this research was to determine the validity and reliability of 
a questionnaire for the development of a plant-based culinary nutrition model for fitness among sports science students. Based on data interpretation by the 13 experts, a questionnaire with 20 items was drafted. The questionnaire drafted was administered to six selected experts in round two for review, feedback, and suggestions. In this round, the redundant items were removed. All items were made into statements and language was corrected structurally. The redundant items were merged and there was one item that was completely removed. In round three, questionnaire was refined and re-sent to the six experts for final review and comments. After modification, the total number of items was 15. Experts were satisfied with the items in the questionnaire and approved it for pilot study.

Table 2 shows the validation of the questionnaire by experts. The criteria for validation were clarity, wordiness, negative wording, overlapping response, balance, use of jargon, appropriateness of responses listed, use of the English Language, and application to praxis. For criteria with scores 3 and 4, there were no changes required to be made on the questionnaire. Significant feedback from experts were important to make the questionnaire credible and subsequently contribute to a valuable research process. All six experts responded to the expert validation form and this indicated the responses for overall questionnaire, which was face validity.

Table 3 shows the opinion of experts on items of the questionnaire and amendments made after round two. It was found that the items were clear, no wordiness, negative wording or jargons. The level of English language was appropriate. Besides that, items that were related to respondents' lifestyle and statements were unbiased. At round three, the experts reviewed the drafted questionnaire as a final step before data collection from respondents. Table 4 presents the experts' concluding comments. At this round, the validated questionnaire had a total of 15 items. The need to develop a plant-based culinary nutrition model for fitness (Part I, Section A) had eight items. However, one out of the eight components in the model (Part II, Section B) was removed due to lack of consensus. Specifically, plant-based Culinary Art (food presentation) was not endorsed by five experts. Therefore, a total of seven items for the components in the model were retained in the survey. The items retained in the final questionnaire are shown in Table 5. Experts' comments were recorded and changes were made accordingly. Some of the changes were standardisation of items from questions into statements, removal of redundant statements or merging of statements, and more precise phrases were added to the instructions in the questionnaire to be more approachable while at the same time ensured that humanising element was present.

CVR and CVI were based on expert advice and the score remained high. Table 5 shows the CVR of questionnaire items. The score of CVR was 0.667 and above for each item, and this was accepted as valid. Only one item was removed from Section B due to lack of consensus among experts. Apart from that, phase 1 of the study resulted in the development of a questionnaire, which included the needs and components, respectively. It had two sections and a total of 15 questionnaire items. Each section scored a CVI of 1.000 and 0.834 , respectively. CVI value was based on CVR calculation of each item in the questionnaire survey.

Reliability analysis is a measure to reflect the construct of the questionnaire items' consistency. Cronbach's alpha is the most common measure used to measure internal consistency reliability (Field, 2009). A reliable instrument should be able to produce similar data from similar respondents in the future. There are varying suggestions to the 
Table 2. Validation of expert panels on the questionnaire $(n=6)$

\begin{tabular}{|c|c|c|c|c|}
\hline No & Criteria & Operational definitions & $\begin{array}{l}\text { Number in } \\
\text { agreement }\end{array}$ & $\begin{array}{l}\text { Validation by } \\
\text { six experts }\end{array}$ \\
\hline 1 & Clarity & $\begin{array}{l}\text { The questions are direct and } \\
\text { specific. } \\
\text { Only one question is asked at a } \\
\text { time. } \\
\text { The participants can understand } \\
\text { what is being asked. } \\
\text { There are no double-barrelled } \\
\text { questions (two questions in one). }\end{array}$ & 6 & $\begin{array}{l}\text { Statements are } \\
\text { clear }\end{array}$ \\
\hline 2 & Wordiness & $\begin{array}{l}\text { Questions are concise. } \\
\text { There are no unnecessary words. }\end{array}$ & 5 & No wordiness \\
\hline 3 & Negative wording & $\begin{array}{l}\text { Questions are asked using the } \\
\text { affirmative (e.g., Instead of asking, } \\
\text { "Which methods are not used?", } \\
\text { the researcher asks, "Which } \\
\text { methods are used?") }\end{array}$ & 6 & $\begin{array}{l}\text { No negative } \\
\text { wording }\end{array}$ \\
\hline 4 & $\begin{array}{l}\text { Overlapping } \\
\text { responses }\end{array}$ & $\begin{array}{l}\text { All possibilities are considered. } \\
\text { There are no ambiguous questions. }\end{array}$ & 5 & No ambiguity \\
\hline 5 & Balance & $\begin{array}{l}\text { The questions are unbiased and } \\
\text { do not lead the participants to a } \\
\text { response. The questions are asked } \\
\text { using a neutral tone. }\end{array}$ & 6 & $\begin{array}{l}\text { Questions are } \\
\text { balanced }\end{array}$ \\
\hline 6 & Use of jargon & $\begin{array}{l}\text { The terms used are understandable } \\
\text { by the target population. } \\
\text { There are no clichés or hyperbole } \\
\text { in the wording of the questions. }\end{array}$ & 6 & No jargon used \\
\hline 7 & $\begin{array}{l}\text { Appropriateness of } \\
\text { responses listed }\end{array}$ & $\begin{array}{l}\text { The choices listed allow } \\
\text { participants to respond } \\
\text { appropriately. } \\
\text { The responses apply to all } \\
\text { situations or offer a way for those } \\
\text { to respond with unique situations. }\end{array}$ & 6 & $\begin{array}{l}\text { Responses } \\
\text { listed are } \\
\text { appropriate }\end{array}$ \\
\hline 8 & $\begin{array}{l}\text { Use of English } \\
\text { language }\end{array}$ & $\begin{array}{l}\text { The use of English Language is } \\
\text { basic and appropriate. } \\
\text { All acronyms are defined. }\end{array}$ & 5 & $\begin{array}{l}\text { English } \\
\text { Language level } \\
\text { is appropriate }\end{array}$ \\
\hline 9 & $\begin{array}{l}\text { Application to } \\
\text { praxis }\end{array}$ & $\begin{array}{l}\text { The questions asked to relate to } \\
\text { the daily practices or expertise of } \\
\text { the potential participants. }\end{array}$ & 6 & $\begin{array}{l}\text { Statements } \\
\text { relate to } \\
\text { participants' } \\
\text { lifestyle }\end{array}$ \\
\hline
\end{tabular}


Table 3. The final comments of expert panels and amendments $(n=6)$

\begin{tabular}{|c|c|c|}
\hline $\begin{array}{l}\text { Expert } \\
\text { Panel }\end{array}$ & Comments & Amendment \\
\hline \multirow[t]{4}{*}{ Expert 1} & $\begin{array}{l}\text { The "note" on page } 2 \text { defines a plant- } \\
\text { based diet - then the first question on } \\
\text { page } 3 \text { asks the respondents to comment } \\
\text { on a definition - I wonder how much the } \\
\text { response to the question on page } 3 \text { will } \\
\text { be biased by the definition already given } \\
\text { on page } 2 \text { ? }\end{array}$ & $\begin{array}{l}\text { No further comments } \\
\text { Re-worded: Culinary is an art of cooking, } \\
\text { nutrition is food science. Both culinary } \\
\text { and nutrition principles learning should } \\
\text { be combined for better physical fitness } \\
\text { management }\end{array}$ \\
\hline & $\begin{array}{l}\text { Section A, Q3 - this statement a slight re- } \\
\text { wording required }\end{array}$ & $\begin{array}{l}\text { No reason just overlooked. Changed } \\
\text { highlight to blue }\end{array}$ \\
\hline & $\begin{array}{l}\text { Section } \mathrm{A}, \mathrm{Q} 8 \text { - is there any reason this } \\
\text { row is highlighted in green rather than } \\
\text { blue (as per the other rows above) }\end{array}$ & \\
\hline & Your survey is looking great! & \\
\hline Expert 2 & This looks good to me! & None \\
\hline Expert 3 & $\begin{array}{l}\text { I still have my reservation on your } \\
\text { definition. You may need to say like } \\
\text { milk, eggs which applies to vegetarians if } \\
\text { different categories. If not the definition of } \\
\text { plant-based diet is not having any animal } \\
\text { products. They can be vegan }\end{array}$ & $\begin{array}{l}\text { A plant-based diet is an eating pattern } \\
\text { that is dominated by minimally processed } \\
\text { plant foods including whole grains, fruits, } \\
\text { vegetables, legumes, nuts and seeds, } \\
\text { perhaps, with limited animal-based } \\
\text { products (dairy or eggs) or no animal- } \\
\text { based products at all. Also commonly } \\
\text { known as vegetarian or vegan diet lifestyle } \\
\text { in Malaysia }\end{array}$ \\
\hline
\end{tabular}

Expert 4 Part II: Section A, No. 3, to add:

...physical fitness to athletic performance and sports

No 5: ....related to performance

Culinary is an art of cooking, nutrition is food science. Both culinary and nutrition principles learning should be combined for better physical fitness management

No changes because this study is not probing into various sports performances.

Expert 5 1. Page 1: Highlighted - Perhaps you can use a more approachable/humanising phrases. E.g., thank you for participating in this questionnaire/survey etc.

2. page 2: Age: Perhaps you could use age range for better quantitative data analysis on the demographic. But if you only have a very small gap of the age group then leave it as it is.

3. Page 3: Again, the use of the term respondent. And you may want to add a description of the items. E.g. The statement below ... Please rate/response ... (Please refer to Section B instruction)

Thank you for completing this survey. We greatly value the information you have provided. Your responses will contribute to the development of plant-based culinary nutrition model for fitness

No changes. Sports science students are bachelor's degree students with age range between 19-25years old

The list below contains views on the need to develop a plant-based culinary nutrition model for fitness. Please mark the range that you think best reflect the need.

None 
Table 4. Items retained in the questionnaire

\begin{tabular}{|c|c|}
\hline Section & Items retained in the questionnaire \\
\hline $\begin{array}{l}\text { A. The need for a plant-based } \\
\text { culinary nutrition model }\end{array}$ & $\begin{array}{l}\text { Responses } \\
\text { 1. Plant-based diet is about consuming food from plants } \\
\text { and fruits ONLY (NO animal-based food products or } \\
\text { ingredients included). } \\
\text { 2. Plant-based diet is an environment friendly diet } \\
\text { 3. Culinary is an art of cooking, nutrition is food science. } \\
\text { Both culinary and nutrition principles learning should } \\
\text { be combined for better physical fitness management } \\
\text { 4. Plant-based culinary nutrition knowledge encourages } \\
\text { healthier cooking and eating lifestyle } \\
\text { 5. Culinary skill is a life skill; Sports Science students } \\
\text { should learn various ways of cooking to prepare } \\
\text { healthy meals } \\
\text { 6. Plant-based culinary nutrition for fitness should be } \\
\text { taught in schools } \\
\text { 7he development of a model for plant-based culinary } \\
\text { nutrition for fitness will provide standard guidelines } \\
\text { for Sports Science students to practice plant based } \\
\text { culinary nutrition lifestyle } \\
\text { 8. Plant-based culinary nutrition should be introduced } \\
\text { as a program in the current sports nutrition course } \\
\text { at higher learning institutions }\end{array}$ \\
\hline B. Components & $\begin{array}{l}\text { 1. Fundamentals of nutrition (plant-based } \\
\text { macronutrients and micronutrients) } \\
\text { 2. Setting up a culinary nutrition kitchen (kitchen tools, } \\
\text { equipment, safety and hygiene) } \\
\text { 3. Plant-based menu planning based on nutritional } \\
\text { needs } \\
\text { 4. Plant-based ingredients substitutions } \\
\text { 5. Plant-based shopping list } \\
\text { 6. Plant-based cooking methods } \\
\text { 7. Culinary herb and spices }\end{array}$ \\
\hline
\end{tabular}

acceptable variance for reliability of between $0.60(60 \%)$ to $0.70(70 \%)$ (Field, 2009). Reliability was measured based on pilot study. The reliability was high for both Section A and Section B. The overall instrument reliability score based on Cronbach's alpha was also high, making it a reliable instrument. As a result, the pilot study provided affirmative reliability scores of the instrument developed, a positive representation of the population about the need to develop a plant-based culinary nutrition model for fitness, and acceptance of the components suggested for the model. The validity and the reliability of the questionnaire were good overall. This questionnaire can therefore be used for data collection to assess the need to develop a plant-based culinary nutrition model for fitness and the culinary components required in the model.

The finalised questionnaire for this research had 15 items with two parts. Part 1 was about demography, whereas Part 2 had two sections. There were eight statements in Section A and seven statements in Section B. For the quantitative part, the validity and reliability of the questionnaire included quantitative and qualitative face validity, quantitative and qualitative content validity, construct validity, and reliability of the tool assessed. 
Table 5. The content validity ratio (CVR) of questionnaire items

\begin{tabular}{llll}
\hline No Statements & CVR & $\begin{array}{c}\text { Accepted or } \\
\text { not accepted }\end{array}$ & Finalised statements \\
\hline
\end{tabular}

Part II - A: The need to develop a plant-based culinary nutrition model for fitness

1 Plant-based diet is about consuming $100 \%$ plants and fruits only (NO animal-based products or ingredients)

2 Plant-based diet is an environment friendly diet

3 Culinary is an art of cooking. Nutrition is food science. Both Culinary and Nutrition should be learnt together for health and fitness

4 Plant-based culinary nutrition knowledge encourages healthy eating

5 In order to cook healthy food, one must have plant-based nutrition knowledge?

6 Cooking is a life skill; everyone should learn various ways of cooking

7 Plant-based culinary nutrition for fitness should be taught in school

8 Personal fitness can be managed through plantbased culinary nutrition

9 Do you agree that plantbased nutrition education for fitness should be supported by culinary skills?

10 To what extent do you agree that culinary skills is a mustlearn skill for sports science students?

11 To what extent do you agree with the development of a model for plant-based culinary nutrition to provide standard guidelines?
0.667 Accepted Plant-based diet is about consuming food from plants and fruits. (Minimal animalbased products or ingredients might be included)

1.000 Accepted Plant-based diet is an environment friendly diet

0.667 Accepted

Culinary is an art of cooking. Nutrition is food science. Both culinary and nutrition principles learning should be combined for better physical fitness management

0.667 Accepted Plant-based culinary nutrition knowledge encourages healthier cooking and eating lifestyle

0.667 Accepted, merged with item 8

0.667 Accepted

Culinary skill is a life skill; Sports Science students should learn various ways of cooking to prepare healthy meals

0.667 Accepted Plant-based culinary nutrition for fitness should be taught in school

0.667 Accepted, merged with item 5

0.667 Accepted, merged with item 6

0.667 Accepted, merged with item 11

1.000 Accepted, The development of a model merged with for plant-based culinary item 10 nutrition for fitness will provide standard guidelines for Sports Science students to practise plant-based culinary nutrition lifestyle 
Table 5. The content validity ratio (CVR) of questionnaire items [Cont'd]

\begin{tabular}{|c|c|c|c|c|}
\hline No & Statements & $C V R$ & $\begin{array}{l}\text { Accepted or } \\
\text { not accepted }\end{array}$ & Finalised statements \\
\hline 12 & $\begin{array}{l}\text { Plant-based culinary } \\
\text { nutrition should be } \\
\text { introduced as a programme } \\
\text { in the current sports } \\
\text { nutrition curriculum at } \\
\text { higher learning institutions }\end{array}$ & 0.667 & Accepted & $\begin{array}{l}\text { Plant-based culinary nutrition } \\
\text { should be introduced as a } \\
\text { programme in the current } \\
\text { sports nutrition course at } \\
\text { higher learning institutions }\end{array}$ \\
\hline \multicolumn{5}{|c|}{$\begin{array}{l}\text { Part II - B: Components in the } \\
\text { model }\end{array}$} \\
\hline 1 & $\begin{array}{l}\text { Fundamentals of nutrition } \\
\text { (whole food, plant-based } \\
\text { macronutrients and } \\
\text { micronutrients) }\end{array}$ & 1.000 & Accepted & $\begin{array}{l}\text { Fundamentals of nutrition } \\
\text { (plant-based macronutrients } \\
\text { and micronutrients) }\end{array}$ \\
\hline 2 & $\begin{array}{l}\text { Setting up a culinary } \\
\text { nutrition kitchen (kitchen } \\
\text { tools, equipment, safety and } \\
\text { hygiene) }\end{array}$ & 1.000 & Accepted & $\begin{array}{l}\text { Setting up a culinary nutrition } \\
\text { kitchen (kitchen tools, } \\
\text { equipment, safety and hygiene) }\end{array}$ \\
\hline 3 & $\begin{array}{l}\text { Whole food plant-based } \\
\text { menu planning based on } \\
\text { nutritional needs }\end{array}$ & 0.667 & Accepted & $\begin{array}{l}\text { Plant-based menu planning } \\
\text { based on nutritional needs }\end{array}$ \\
\hline 4 & $\begin{array}{l}\text { Plant-based ingredient } \\
\text { substitutions }\end{array}$ & 1.000 & Accepted & $\begin{array}{l}\text { Plant-based ingredient } \\
\text { substitutions }\end{array}$ \\
\hline 5 & $\begin{array}{l}\text { Whole food plant-based } \\
\text { shopping list }\end{array}$ & 1.000 & Accepted & Plant-based shopping List \\
\hline 6 & Plant-based cooking methods & 1.000 & Accepted & Plant-based cooking methods \\
\hline 7 & Culinary herb and spices & 1.000 & Accepted & Culinary herb and spices \\
\hline 8 & $\begin{array}{l}\text { Plant-based culinary art (food } \\
\text { presentation) }\end{array}$ & 0.333 & Not accepted & \\
\hline
\end{tabular}

Reliability was achieved through pilot test. For this research, Cronbach's alpha score of above 0.7 was considered reliable. This was based on George \& Mallery (2003) and the rule of thumb for alpha coefficients by Gliem \& Glim (2003). The analysis was run on Section $A$ and Section B of the questionnaire separately. The questionnaire items from Section A scored 0.709 and Section $\mathrm{B}$ had a score of 0.832 . The 15 items had a mean score of between 3.800 and 4.430 each, and the standard deviation was between 0.568 and 0.964 . Accordingly, the internal consistency of the entire 15-item instrument was demonstrated by Cronbach's alpha at 0.836. However, no item was deleted to improve the score as the overall reliability of the instrument was 0.836 , which was considered acceptable. The results obtained were consistent with the findings from Kliemann et al. (2016). The authors found that the reliability of the updated version of the general nutrition knowledge questionnaire was greater than 0.7. This indicated that their updated scale had good reliability. Besides that, Eshaghi et al. (2020) reported that the Persian version of questionnaire was acceptable because it scored more than 0.80 .

This model basically imparts culinary skills with plant-based nutrition knowledge. The model has two parts with seven components: (a) 
Fundamentals of nutrition (plant-based macronutrients and micronutrients), (b) Setting up a culinary nutrition kitchen, (c) Plant-based menu planning, (d) Plant-based ingredients substitutions, (e) Plant-based shopping list, (f) Plantbased cooking methods, and (g) Culinary herbs and spices. The fundamentals of nutrition and culinary skills should be applied in daily food consumption to maintain fitness. This research has adopted the power plate as part of its model, which is a guidance for a balanced plant-based food consumption daily. The Power Plate was created by the experts at Physicians Committee for Responsible Medicine (PCRM, 2014). Power plate for fitness features vegetables, fruits, whole grains and legumes, which are essential for health management. All seven components listed had CVR and CVI value of 1 unanimously, which indicated maximum consensus for each component. Content analysis was done, then followed by CVR and CVI of the questionnaire items. The findings proposed that the questionnaire for a plant-based culinary nutrition model for fitness among sports science students was a valid and reliable survey instrument for data collection.

\section{Strengths and limitations}

This was a mixed method research, which is a new contemporary wave in science methodology (Petrovic, Koprivica $\&$ Bokan, 2017). The integration of qualitative and quantitative methods provide an innovative way that enables researcher to gain opinions from experts to understand the complex and sensitive issues in sports nutrition. Plant-based culinary nutrition model is related to real health and fitness issues among athletes. Optimistically, this research will engage people and policy makers to improve the fitness level of athletes and possibly the nation. However, the study population was limited to sports science students in Klang Valley. As a result, they only represent a small part of the Malaysian sports science student population.

\section{CONCLUSION}

The questionnaire for a plant-based culinary nutrition model for fitness among sports science students was validated and tested for reliability. Cronbach's alpha score was 0.836 with a total of 15 items. The questionnaire items from both Sections A and B were statistically reliable, with a score of 0.709 and 0.832 , respectively. Hence, a questionnaire on a plant-based culinary nutrition model for fitness among sports science students that is reliable for data collection has been developed.

\section{Acknowledgement}

The authors acknowledge the panel of 13 experts for their guidance and sincere appreciation to all respondents for their enthusiasm and support during the pilot study.

\section{Authors' contributions}

BBM, principal investigator, conceptualised the study, prepared the draft of the manuscript; AZAR and $\mathrm{SHH}$, advised on data analysis and interpretation, and reviewed the study design. All authors reviewed the manuscript and approved the final version of the manuscript.

\section{Conflict of interest}

The authors declare that they have no conflict of interests.

\section{References}

Ayre CA \& Scally AJ (2014). Critical values for Lawshe's content validity ratio: Revisiting the original methods of calculation. Meas Eval Couns Dev 47(1):79-86. https://doi. org/10.1177/0748175613513808

Barton KL, Wrieden WL \& Anderson AS (2011). Validity and reliability of a short questionnaire for assessing the impact of cooking skills interventions. J Hum Nutr Diet 24:588-595.

Browne RH (1995). On the use of a pilot sample for sample size determination. Stat Med 14(17):1933-1940.

Burke LM \& Hawley JA (2018). Swifter, higher, stronger: What's on the menu? Science 362(6416):781-787. From http://science. sciencemag.org/ [Retrieved January 7, 2019]. 
Caraher M (2015). Cooking in crises: Lessons from the UK. From http://arrow.dit.ie/cgi/ viewcontent. cgi ?article $=1006 \&$ context $=\mathrm{dg}$. [Retrieved April 242017.

Condrasky MD \& Hegler M (2010). How culinary nutrition can save the health of a nation. $J$ Ext 48(2): $1-6$.

Eshaghi E, Rahmati-Najarkolaei F, Yekaninejad M \& Rostami H (2020). Psychometric evaluation of the Persian version of dietary habits questionnaire and nutrition knowledge questionnaire for adults among medical staffs. Shiraz Med J 21(5).

Evans J (2015). Plant-based nutrition: Will your next prescription be the farmers market or the pharmacy? Beginnings 35(2):28-29.

Field A (2009). Discovering statistics using SPSS (3rd ed.). SAGE Publications, California. From http: / / en.bookfi.nets / ?q=andy+fields \&e= $1 \& \mathrm{t}=0 . \% 20019$ [Retrieved October 10 2019].

George D \& Mallery P (2003). SPSS for Windows step by step: A simple guide and reference. 11.0 update (4th ed.). Boston: Allyn \& Bacon.

Gliem J \& Glim R (2003). Calculating, interpreting, and reporting Cronbach's alpha reliability coefficient for likert-type scales [Presentation]. Midwest Research to Practice Conference in Adult, Continuing, and Community Education, Columbus, Ohio.

Hever J (2016). Plant-based diets: A physician's guide. Perm J Summer 20(3):15-82. https:// doi.org/10.7812/TPP/15-082

Hsu CC (2007). The Delphi technique: Making sense of consensus. Pract Assess Res Evaluation 12(10):1-8.

Kliemann N, Wardle J, Johnson F \& Croker H (2016). Reliability and validity of a revised version of the general nutrition knowledge questionnaire. Eur J Clin Nutr 70(10):11741180. doi: 10.1038/ejcn.2016.87

Koonce GL \& Kelly MD (2014). Analysis of the reliability and validity of a mentor's assessment for principal internships. Educ Leadersh Rev $15(2): 33-48$.

Lawshe $\mathrm{CH}$ (1975). A quantitative approach to content validity. Pers Psychol 28(4):563-575.

McAnulty L, Holden H \& Keith R (2001). Eating before, during, and after the event (2nd ed.). CRC Press, Florida. https://doi. org/10.1201/9781420036916.ch12.

Oluwatayo JA (2012). Validity and reliability issues in educational research. Journal of Educational and Social Research 2(2):391-400. https: / / doi. org/10.5901/jesr.2012.v2n2.391
Onwuegbuzie AJ, Frels RK \& Hwang E (2016). Mapping Saldăa's coding methods onto the literature review process. Journal of Educational Issues 2(1):130. https://doi.org/10.5296/jei. v2i1.8931

PASS Sample Size Software (2019). Pilot Study Sample Size Rules of Thumb. From https:// www.ncss.com/ [Retrieved November 30 2019].

PCRM (2014). Food power for athletes. Physicians Committee for Responsible Medicine. From https://www.pcrm.org/good-nutrition / nutrition-for-athletes [Retrieved January 14 2018].

Petrovic A, Koprivica V \& Bokan B (2017). Quantitative, qualitative, and mixed research in sport science: A methodological report. S Afr $J$ Res Sport Phys Educ Recreat 39(2):181-197.

Rahbari MM, Shariati M, Keramat A, Yunesian M, Eslami M, Mousavi SA \& Montazeri A (2015). Content validity of national post marriage educational program using mixed methods. Iran J Public Health 44(4):535.

Simon MK \& White J (2016). Survey/interview validation rubric for expert panel-VREP (thesis). From dissertationrecipes.com/ wp-content/uploads/2011/04/ExpertValidation-v3.pdf. [Retrieved October 4 2019].

Thangaratinam S \& Redman CW (2005). The Delphi technique. The Obstet Gynaecol 7(2):120-125. https://doi.org/10.1576/toag.7.2.120.27071

Tong A, Sainsbury P \& Craig J (2018). Consolidated criteria for reporting qualitative research: A 32item checklist for interviews and focus groups. Int $J$ Qual Health Care 19(6):349-357.

Venderley AM \& Campbell WW (2006). Vegetarian diets: Nutritional considerations for athletes. Sports Med 36(4):293-305. doi:10.2165/00007256-200636040-00002.

White TL \& McBurney DH (2012). Research methods. Cengage Learning.

Wirnitzer KC (2018). Vegan nutrition: Latest boom in health and exercise. In Therapeutic, Probiotic, and Unconventional Foods (pp. 387453). Academic Press. 